\title{
LA VIDA COMO PROYECTO Y SENTIDO
}

\author{
GUILLEM TURRÓ ORTEGA \\ Universitat Ramon Llull \\ MIQUEL SEGURÓ MENDLEWICZ \\ Universitat Oberta de Catalunya \\ Universitat Ramon Llull
}

\begin{abstract}
RESUMEN: El propósito de este artículo es aproximarnos al tratamiento que la cuestión del sentido antropológico ha recibido por parte de dos egregios filósofos españoles. El primer gran bloque estará dedicado a explorar - siguiendo a José Ortega y Gasset - cómo la vida auténtica es genuinamente proyectiva, una empresa mediante la cual se despliega el sentido personal. De este modo podremos ahondar en nociones tan relevantes como la vocación, el destino o el fondo insobornable. En la segunda y última parte, José Gómez Caffarena nos ayudará a cuestionar si la experiencia de sentido es indisociable de la gran pregunta por el Sentido, entendido como el horizonte meta-físico de la vida humana.
\end{abstract}

PALABRAS CLAVE: proyecto; autenticidad; vocación; vida; sentido.

\section{Life as Project and meaning}

ABSTRACT: This paper aims to analyze the question of the anthropological sense in two egregious Spanish philosophers. The first great block will be devoted to exploring - following José Ortega y Gasset - how authentic life is genuinely projective, in which personal meaning is developed. In this way we can delve into notions as relevant as the vocation, the destiny or the fund incorruptible of existence. In the second and last part, José Gómez Caffarena will help us to ask on whether the experience of meaning is inseparable from the great question for the Sense, understood as the metaphysical horizon of human life. KEY WORDS: project; authenticity; vocation; life; meaning.

\section{Planteamiento}

¿Por qué existe el ser y no más bien la nada? Esta pregunta es la más radical de la existencia humana. Así lo glosaron Leibniz y Heidegger en virtud de la contingencia y finitud vividas. La cuestión parece indescifrable, y por eso ocupa un privilegiado lugar dentro de la reflexión metafísica, que es el terreno de las grandes preguntas de la experiencia humana, corazón de la reflexión filosófica.

La metafísica, que Kant define en el Prólogo de la segunda edición de la Crítica de la razón pura (1787) como el campo de batalla de las grandes preguntas, es la disciplina donde la finitud se destila con mayor claridad. El mismo 
Kant lo expresa de la siguiente manera: los seres humanos tenemos el peculiar destino de estar acechados por cuestiones a las que no podemos responder, y sin embargo no podemos desterrar completamente. Porque puede que las pospongamos hasta el momento crucial, único, del morir. Pero tarde o temprano aparecen en la conciencia de forma implacable, poniendo en jaque el nervio mismo de la existencia.

Sin embargo, hay cuestiones radicales y fundamentales que tienen que ver con la vida de cada uno, que son insoslayables y que no permiten una abstracción genérica como pueda ser la pregunta por el «ser». Una de esas cuestiones es sin duda la del «sentido», que atañe más a la vida particular y su concreción que con la vivencia absoluta, en sí o nouménica, del sentido de «la» vida como problema. Tanto el teleologismo aristotélico como el deontologismo kantiano parten de la premisa de que las cosas que hacemos tienen la necesidad de ser vividas con «sentido». Parece que aquí no puede uno dejarlo para más tarde, para el lecho de muerte. La vida demanda ser vivida con un propósito, una causa eficiente y final, dicho a la aristotélica, como ingrediente indispensable. Es más, para Viktor Frankl, autor al que nos referiremos más tarde, nada hay en el mundo capaz de ayudarnos a sobrevivir, aun en las peores condiciones, como el hecho de saber que la vida tiene un sentido.

En este artículo hemos elaborado una reflexión en torno al sentido de la vida humana. Nuestro planteamiento se inspira en las ideas de dos insignes filósofos españoles: José Ortega y Gasset y José Gómez Caffarena. En primer lugar, esbozamos una aproximación a la vida auténtica basándonos en el pensamiento de Ortega. Es la parte más sustancial de este artículo y de mayor protagonismo temático. La autenticidad es inseparable de otros conceptos orteguianos sin los cuales pierde buena parte de su consistencia filosófica. Proyecto, vocación, destino, fondo insobornable, misión, entelequia o quehacer aparecen interconectados en una trama que tiene por eje radial la cuestión de la autenticidad. Pero nuestro propósito ha sido focalizar la atención en el proyecto. La vida auténtica es genuinamente proyectiva, es una obra mediante la cual se despliega un sentido personal. Luego nos preguntamos si la vivencia de sentido tiene que ir acompañada de la gran pregunta por el Sentido, entendido como el entramado meta-físico de la vida en su generalidad y totalidad. Ahí es donde la propuesta metafísica de José Gómez Caffarena cobra protagonismo, puesto que su reflexión supone, aun partiendo en cierto modo del núcleo filosófico orteguiano y haciendo uso de algunos de sus recursos temáticos, un reverso a la propuesta más intramundana de Ortega.

\section{La Vida auténtica SEgún ORtega y Gasset: un proyecto con SENTido}

\section{I}

Para Ortega y Gasset (1883-1955) uno de elementos clave de la vida auténtica es el proyecto.

El hombre auténtico ha dispuesto su vida a una empresa, se entrega a un propósito con el que se compromete plenamente. Podemos apreciar que 
nuestra vida tiene una misión cuando ejecutamos nuestro destino, cuando lo asumimos y lo convertimos en vida personal. Al encontrarnos viviendo descubriremos ya formado nuestro proyecto de vida. Este plan de actuación nos marca el rumbo a seguir en nuestra andadura vital. Ortega entiende la vida como un proyecto que se hace y rehace en función de un designio vocacional. Vivir auténticamente concierne al despliegue efectivo de lo que sólo existía germinalmente, es decir, pro-yectivamente. Escribe: «el factor más importante de la condición humana es el proyecto de vida que inspira y dirige todos nuestros actos. Cuando las circunstancias nos estorban o impiden ser el personaje anticipado que constituye nuestra más auténtica realidad, nos sentimos profundamente inhibidos» ${ }^{1}$. La exigencia y el ahínco por conseguir lo que nos hemos propuesto son inherentes a la autenticidad. Se trata de encarar la vida como un proyecto no formulado, que tenemos que imaginar, inventar o forjar. Vivir es convertir el proyecto abstracto y genérico en proyecto singular y personal ${ }^{2}$.

Poco a poco apreciaremos si el trazado de nuestra vida coincide o diverge respecto a nuestra vocación. Debido a que no existe ningún proyecto común o ajeno a mi medida, tendré que inventar y apropiarme mi proyecto vital. Este destino será nuestro auténtico ser. Escribe Ortega: «Nuestra voluntad es libre para realizar o no ese proyecto vital que últimamente somos, pero no puede corregirlo, cambiarlo, prescindir de él o sustituirlo. Somos indeleblemente ese único personaje programático que necesita realizarse. El mundo en torno o nuestro propio carácter nos facilitan o dificultan más o menos esa realización. La vida es constitutivamente un drama, porque es la lucha frenética con las cosas y aún con nuestro carácter por conseguir ser de hecho el que somos en proyecto» ${ }^{3}$. La vida es una realidad biográfica henchida de tensión dramática. Esto significa que pueda desembocar en tragedia vital; esto ocurre cuando no nos reconciliamos con nuestra mismidad. Lo expresa así: «Todo destino es dramático y trágico en su profunda dimensión. Quien no haya sentido en la mano

\footnotetext{
1 Ortega y Gasset, J., Artículos (1935-1937), O.C. V, 239.

2 Ortega y Gasset, J., Goethe desde dentro, O.C. IV, 400: "No hay un vivir abstracto. Vida significa la inexorable forzosidad de realizar el proyecto de existencia que cada cual es. Este proyecto en que consiste el yo no es una idea o plan ideado por el hombre y libremente elegido. Es anterior, en el sentido de independiente, a todas las ideas que su inteligencia forme, a todas las decisiones de su voluntad. Más aún, de ordinario no tenemos de él sino un vago conocimiento. Sin embargo, es nuestro auténtico ser, es nuestro destino. Nuestra voluntad es libre para realizar o no ese proyecto vital que últimamente somos, pero no puede corregirlo, cambiarlo, prescindir de él o sustituirlo». ORtega y GASSET, J, O.C. II, p. 38: «El deber no es único y genérico. Cada cual traemos el nuestro inalienable y exclusivo. Para regir mi conducta Kant me ofrece un criterio: que quiera siempre lo que otro cualquiera pueda querer. Pero esto vacía el ideal, lo convierte en un mascarón jurídico y en una careta de facciones mostrencas. Yo no puedo querer plenamente sino lo que en mí brota como apetencia de toda mi individual persona».

3 Ortega y Gasset, J., Goethe desde dentro, O.C. IV, 400. Ibídem., p. 401: «Y aquí surge lo más sorprendente del drama vital: el hombre posee un amplio margen de libertad con respecto a su yo o destino. Puede negarse a realizarlo, puede ser infiel a sí mismo. Entonces su vida carece de autenticidad».
} 
palpitar el peligro del tiempo, no ha llegado a la entraña del destino, no ha hecho más que acariciar su mórbida mejilla» ${ }^{4}$.

Más, por otra parte, esta creación tiene que contar con el beneplácito de mi destino personal. La moral no es lo que el hombre debe ser sino, simplemente, su ser inexorable ${ }^{5}$. Reproduzcamos este espléndido pasaje: «Me irrita este vocablo "moral". Me irrita porque en su uso y abuso tradicionales se entiende por moral no sé bien qué añadido de ornamento puesto a la vida y ser de un hombre o de un pueblo. Por eso yo prefiero que el lector lo entienda por lo que significa, no en la contraposición moral-inmoral, sino en el sentido que adquiere cuando de alguien se dice que está desmoralizado. Entonces se advierte que la moral no es una performance suplementaria y lujosa que el hombre añade a su ser para obtener un premio, sino que es el ser mismo del hombre cuando está en su propio quicio y vital eficiencia. Un hombre desmoralizado es simplemente un hombre que no está en posesión de sí mismo, que está fuera de su radical autenticidad y por ello no vive su vida y por ello no crea ni fecunda ni hinche su destino. Para mí la moral no es lo que el hombre debe ser, pero por lo visto puede prescindir de ser, sino que es simplemente el ser inexorable de cada hombre, de cada pueblo» ${ }^{6}$.

El enorme interés filosófico que presenta este fragmento merece algunas apostillas. En primer lugar cabe resaltar su nítida apuesta por una moral ontológica. Sería un craso error considerar la moral como un mero accesorio del que podemos prescindir. La moral conforma nuestro ser, configura nuestro ethos, nos constituye como personas. Fue Aranguren quien propugnó la moral como estructura. El hombre inauténtico es un ser des-virtuado, cuando virtus (la traducción latina del griego areté) es virtud pero también excelencia, potencia o fuerza ${ }^{7}$. Sin fortaleza anímica nos será imposible elevarnos moralmente. Los antiguos nos enseñaron que el alma era el principio de vida. Por tanto, una vida des-moralizada es también un vida sin alma, des-animada y sin ímpetu. Una persona desmoralizada tiene poca talla moral y está desmotivada ${ }^{8}$. Carentes de vocación no se siente impulsada a desplegar su humanidad. La autenticidad es una vida en forma, como ha escrito Cortina: «Recuperando el significado deportivo del término castellano, el individuo alto de moral es el que sigue un entrenamiento, el que a lo largo de su vida va ejercitándose para

4 Ortega y Gasset, J., La rebelión de las masas, p. 151. Marías, J., Ensayos de teoría. p. 91: «El hombre no tiene más remedio que acertar y elegir bien, porque se juega la vida en cada decisión, en cada elección. Por esto su vida es drama, como Ortega repite una vez y otra».

5 Ortega y Gasset, J., Artículos 1930, O.C. IV, p. 73.

6 Ortega y Gasset, J., Porque he escrito el hombre a la defensiva, O.C. IV, p. 72

7 Ortega y Gasset, J., "Historia de la filosofía», de Émile Brehier, O.C. VI, pp. 400-401: «Platón no emplea en este último lugar la palabra "virtud" que yo introduzco, pero está latiendo en todo el trozo, porque la idea griega de "virtud" —areté- significa precisamente "autenticidad", es decir, "capacidad efectiva" o simplemente "efectividad" para algo, ser en plena realidad lo que es. Todo lo viviente tiene su areté, su virtud, a saber, su modo plenario de ser».

8 Bilbao, G., «Profesional responsable y ciudadano comprometido» en Profesionales y vida pública (ed. Hortal, A., y EtXeberria, X.), Bilbao, Ed. Desclée De Brouwer, 2011, p. 293. 
poder responder con gallardía a los retos vitales» ${ }^{9}$. Por tanto, una vida des-moralizada es también un vida sin alma o des-animada. Una vida inauténtica es una existencia des-vitalizada y des-integrada. Conviene recordar que conceptos como desmoralizar, desanimar, desmotivar, descorazonar y desalentar comparten un mismo aire de familia. Por otra parte, Ortega utiliza tres verbos muy significativos para calificar la incapacidad para ser auténticos: crear, fecundar e hinchar. Este último merece un pequeño apunte. Sin aire (en griego pneuma, en latín spiritus) no podremos insuflar nuestro ser. Por tanto, nos resultará imposible volar y elevarnos hacia las alturas de uno mismo. Tanto pneuma como spiritus también pueden traducirse por aliento, de donde proviene des-alentar. El propio Ortega comenta que alegría proviene de aligerar o perder peso (del verbo alacer). La persona auténtica — liberada de la pesadumbre- se siente ingrávida y se eleva jovialmente ${ }^{10}$. Citémosle: «En la alegría nuestra vida adquiere una emoción aerostática y parece que se levanta, flota leve en todo momento ${ }^{11}$.

El texto de Ortega que acabamos de citar continua de este modo: «Por eso, desde siempre y una vez más en mis conferencias últimas de Buenos Aires, cuando anunciaba yo un posible curso de Ética — que ya no sé bien si haréproclamaba como imperativo fundamental de la mía el grito del viejo Píndaro. Guenoio hos eisi-llega a ser el que eres ${ }^{12}$. Ortega asume la exigencia pindárica como una norma moral fundamental: atrévete a ser el que eres, sé fiel a ti mismo. El verso del poeta arcaico expresa su ética heroica: «iHazte el que eres!, como aprendido tienes» ${ }^{13}$. Es importante tener en cuenta que Píndaro —que vivió en el siglo VI a.C.— exaltará en sus odas los valores aristocráticos y agonales representados por los atletas vencedores en los Juegos Olímpicos. Es probable que Ortega conociera esta máxima leyendo a Nietzsche, un autor que ejercerá una remarcable influencia en aquella época ${ }^{14}$. Se trata de una máxima muy apreciada por Nietzsche; verbigracia, el subtítulo de Ecce Homo es Cómo se llega a ser lo que se es (Wie man wird, was man ist). Es importante remarcar su condición de filólogo clásico, y por ende, de sobresaliente conocedor de la literatura griega.

Egregios filósofos — por ejemplo Kant o Stuart Mill— han compendiado su ética en forma de imperativo. Mediante la realización de este precepto quedaría justificado nuestro comportamiento moral. Ortega aboga por otro criterio para imperar nuestras acciones. Se trata de ser testimonios de la vocación enraizada en nuestra interioridad. Tenemos que acatar una obligación que brota

9 Contina, A., Ética aplicada y democracia radical. Tecnos, Madrid 1993, p. 179.

10 Ortega y Gasset, J., Unas lecciones de metafísica, O.C. XII, p. 37.

11 Ortega y Gasset, J., La caza y los toros, O.C. IX, p. 455.

12 Ortega y Gasset, J., Artículos 1939, O.C. IV, p. 73. J. Ortega y Gasset, El Espectador I, O.C. II, p. 38. "No midamos, pues, a cada cual sino consigo mismo: lo que es como realidad con lo que es como proyecto. "Llega ser el que eres". He ahí el justo imperativo...»

13 Píndaro, Odas y fragmentos. Pítica II, p. 152.

14 Sobejano, G., Nietzsche en España. p. 551 
de uno mismo, un imperativo que forma parte de nuestra propia realidad ${ }^{15}$. Esta exigencia de autenticidad nos impide vivir de cualquier modo. Nuestro yo (vocación o fondo insobornable) es un ser misterioso que íntimamente nos exhorta a ser lo que tenemos que ser. Escribe Ortega: «Esa íntima conciencia constantemente nos dice quién es ese que tenemos que ser, esa persona o personaje que tenemos que esforzarnos en realizar, y nos lo dice con una misteriosa voz interior que habla y no suena, una voz silente que no necesita palabras, que es, por rara condición, a un tiempo monólogo y diálogo, voz que, como un hilo de agua, asciende en nosotros de un hontanar profundo, que nos susurra el mandamiento de Píndaro: "llega a ser el que eres" ${ }^{16}$. Se trata de un mandato que resonará de modo recurrente a lo largo de su obra. Prescindir de ella es abandonarnos a la pura facticidad, condenarnos a errar a la deriva ${ }^{17}$.

Desde ahora podremos hablar de una ética teleológica — sólo parcialmente inspirada en la aristotélica- sintetizada mediante el lema pindárico. Se trata de una propuesta ética vertebrada a partir de una finalidad (télos) que guiará nuestros pasos en función de un horizonte, meta o destino. Citémosle nuevamente: «El hombre está dispuesto a derramar su vida precisamente por algo que sea capaz de llenarla. Esto es lo que llamamos el ideal. Para vivir con plenitud necesitamos un algo encantador y perfecto que llene exactamente el hueco de nuestro corazón. [...] En el comienzo de su Ética, dice Aristóteles: "Busca el arquero con la mirada un blanco para sus flechas, ¿y no lo buscaremos para nuestras vidas?" Bajo tal metáfora pierde la Ética el cariz pedantesco que en nuestro tiempo ha tomado, y parece convertirse en una noble disciplina deportiva, que puede resumir sus imperativos así: ¡Hombres, sed buenos arqueros!» ${ }^{18}$. En sintonía con el Estagirita, Ortega considera que el símil del arquero refleja bien el sentido de la vida humana ${ }^{19}$. La imagen empleada se entenderá mejor si tenemos en cuenta que en griego vida (bíos) y arco (biós) solo difieren por un acento ${ }^{20}$. Ortega escribe lo siguiente: «Ahora, bien que sea una realidad consistente en actividad, dice

15 Ortega y Gasset, J., Pidiendo un Goethe desde dentro, O.C. IV, p. 406. Ortega y Gasset, J., Prólogo para alemanes, O.C. VIII, p. 28: «La necesidad humana es el terrible imperativo de autenticidad».

16 Ortega y Gasset, J., Vives-Goethe, O.C. IX, pp. 513-514

17 García Astrada, A., El pensamiento de Ortega y Gasset, Troquel, Buenos Aires, 1961, pp. $74-75$

18 Ortega y Gasset, J., Teoría de Andalucía y otros ensayos, O.C. VI, p. 137. "Seamos con nuestras vidas como arqueros que tienen un blanco». Estas palabras de Aristóteles que pertenecen a su Ética a Nicómaco pueden leerse como cita introductoria de textos como El Espectador II. O.C. II p. 127 y El Espectador III. O.C. II p. 226. En este último caso van acompañadas del Fragmento 51 de Heráclito: «No comprendo cómo la realidad, discrepando de sí misma, concuerda consigo misma: armonía de lo antagónico como el arco y la lira».

19 Aristóteles, Ética Nicomáquea (1094a 23-24): «Si existe algún fin de nuestros actos que queramos por él mismo y los demás por él, [...] es evidente que ese fin será lo bueno y lo mejor. Y así, ¿no tendrá su conocimiento gran influencia sobre nuestras vidas y, como arqueros que tienen un blanco, no alcanzaremos mejor el que debemos alcanzar».

20 Recordemos el Fragmento 48 de Heráclito: «Nombre del Arco es Vida pero su obra es muerte». 
Leibniz, arcus tensi illustrari potest, puede representarse por un arco tenso hacia algo. Por eso, desde mis veinte años la portada de mis libros españoles lleva un arquerito salvaje lanzando su flecha. Pertenezco a la tribu de los flecheros $»^{21}$. Evidentemente, no es anecdótico que Ortega titule su colección de obras dentro de la Revista de Occidente con este bello nombre: El Arquero.

La existencia se asemeja a una flecha que vuela gracias al impulso de un arco. Fue Nietzsche - en su obra Así habló Zaratustra - quien comparó la existencia humana con una flecha de anhelo hacia la otra orilla. Los humanos -al mismo tiempo naturales y sobrenaturales - somos criaturas fronterizas, una especie de centauro ontológico. Somos un sagitario infatigable que dispara sobre blancos incitantes. Ortega coincidirá con una concepción griega de la vida como un continuo dinamismo dirigido a un fin (télos) o blanco vital ${ }^{22}$. Para disparar el arco debemos ser capaces de empuñarlo con una mano y tensarlo con la otra. Sin un buen pulso y mucha fuerza nunca lo lograremos. Para que la flecha vuele lejos y alcance el objetivo previsto imprimiremos potencia a nuestro disparo. De lo contrario malograremos nuestra misión. Escribe Ortega: «Es el puño que retrocede para tender el arco. Gracias a este retroceso, la flecha se cargará de ímpetu e irá a hincarse en lo remoto ${ }^{23}$. Pero también deberemos apuntar bien, concentrando nuestra mirada en un punto específico. En nuestra vida hay una tarea crucial, a saber, el momento en que el arquero queda en suspenso y elige su blanco. Tendremos que identificar un buen propósito para lograr que nuestra existencia alcance su mejor versión. La única manera de realizarnos humanamente es que nuestra vida tenga un sentido moral certero. El hombre auténtico habrá atinado en fijar la meta adecuada. En cambio, errará todo aquel que no detecte el blanco correcto.

Avanzar por la senda de la autenticidad conlleva descubrirse como entelequia: «Cuando tratando de contestar a la pregunta misma que antes he hecho, al angustioso ¿quién soy yo?, él se respondía: una entelequia, empleaba tal vez el vocablo mejor para designar ese proyecto vital, esa vocación inexorable en que nuestro auténtico yo consiste. Cada cual es "el que tiene que llegar a ser", aunque acaso no consiga ser nunca ${ }^{24}$. La noción de entelequia forma parte

21 Ortega y Gasset, J., Meditación de Europa, O.C. IX, p. 279.

22 Lalcona, J. F., El Idealismo político de Ortega y Gasset. Un análisis sintético de la evolución de su filosofía política, Editorial cuadernos para el diálogo, Madrid, 1974. p. 348. Nicol, E., La vocación humana, México, Fondo de Cultura Económica, 1953, p. 42: «La vida tiende a un fin por sí misma, aunque a veces no sepamos dárselo, como el pensamiento tiende a la verdad, aunque no salgamos de nuestras dudas o vayamos de ellas al error. Estamos entonces como en la situación de un arco, tirante en manos del arquero que no tuviese flechas con que hacer el disparo; con una fuerza acumulada que no tiene empleo. Pero la fuerza misma es afirmación de la vida».

23 Ortega y Gasset, J., Sobre la razón histórica, O.C. XII, p. 167.

24 Ortega y Gasset, J., Pidiendo un Goethe desde dentro, O.C. IV, 405. En la p. 415 de esta misma obra podemos leer estas palabras: «Porque vivir es precisamente la inexorable forzosidad de determinarse, de encajar en su destino exclusivo, de aceptarlo, es decir, resolverse a serlo. Tenemos, queramos o no, que realizar nuestro "personaje", nuestra 
de la filosofía aristotélica, entendida como la actualización perfecta de un ser. Muchos siglos después, Leibniz recuperará este concepto para su metafísica monadológica. Con esta noción denomina a las mónadas, en tanto que engloban una determinada perfección ${ }^{25}$. Pero Ortega le adjudicará a este concepto un significado distinto. Cada persona detenta un fin en sí mismo; la existencia es una senda que tenemos que acometer a fin de realizarnos auténticamente. Nuestra personalidad es similar a una entelékheia y a un daimon ${ }^{26}$.

\section{II}

Nuestro ser alberga una finalidad y un sentido (télos) que espera ser realizada. Larvadamente la vida contiene una dirección perfectiva denominada entelequia. Recordemos que teleiosis significa perfección. Existir es realizarse en función de una pre-tensión propia e intransferible, pues la vida auténtica se proyecta desplegando su vocación. Sólo así lograremos nuestra perfección moral. Según Aranguren, Ortega preconiza una moral de la perfección ${ }^{27}$. En este sentido, solo alcanzando la plenitud de nuestro ser podremos ser felices.

Vivir de manera auténtica presupone revelar nuestro destino más genuino. Aristóteles nos dice que vivir exige plantearnos una meta final, un télos. De manera muy parecida a cómo el arquero apunta a un blanco determinado, debemos proponernos un fin para poder encarrilar nuestra conducta. Esto significa que nuestra vida se asemeja a un proyectil propulsado por un esfuerzo persistente. El origen del término esfuerzo es la raíz latina fortis precedida por el prefijo ex, lo cual indica la idea de un movimiento hacia afuera. El esfuerzo siempre implica actuar movilizando nuestras fuerzas para vencer una resistencia interior o exterior. Como asevera Lledó, la flecha es la vida cuya andadura dibuja el sentido de una trayectoria. Lo importante es el impulso y energía que mueve nuestra existencia pero también la orientación que perfila el recorrido. Télos no significa tanto «finalidad», cuanto «cumplimiento», «plenitud», «consumación», «madurez» ${ }^{28}$. Aristóteles nos invita a trazar nuestro camino con arreglo a un fin último o bien supremo (felicidad o eudaimonia). No en balde la vida humana es un proyecto esencialmente dinámico (de dynamis, "potencia», "poder» o «capacidad») que apunta en dirección a la plena realización de nuestras potencialidades.

En consonancia con Leibniz y Fichte la realidad no es forma sino vis activa ${ }^{29}$. El hombre combina un ser inercial (receptivo, tradicional) y un ser ágil

vocación, nuestro programa vital, nuestra "entelequia". Por falta de nombres para esa terrible realidad que es nuestro auténtico yo, no quedará».

${ }_{25}$ Recordemos que Ortega fue un gran conocedor de la filosofía de Leibniz. Prueba de ello es su espléndida obra La idea de principio en Leibniz.

26 Ortega y Gasset, J., Vives-Goethe, O.C. IX, p. 559.

27 Aranguren, J. L., La ética de Ortega, Madrid, Taurus, 1958, p. 42.

28 Lledó, E., "Aristóteles y la ética de la "polis"», en V. CAmps (ed.), Historia de la ética. 1. De los griegos al Renacimiento, p. 146.

29 ORTEga y GaSSET, J., Kant, O.C. IX, p. 47: «La posición pasiva queda abolida y existir significa esforzarse. Dondequiera que la pura inspiración germánica sopla germina un principio activista, dinámico, voluntarista. A la física de Descartes, que es inerte geometría, Leibniz agrega la noción 
(emprendedor, afrontador de problemas) ${ }^{30}$. La vida es vis proiectiva, un movimiento que parte de un punto (terminus a quo) para dirigirse a una meta (terminus ad quem) ${ }^{31}$. Es un proceso que puede ser calificado de entelequia, como un tra-yecto impulsado por una vis proiectiva. Recordemos que destino también puede ser destinación, es decir, la meta o punto de llegada, el lugar al que nos encaminamos. El curso que debemos seguir depende principalmente de nuestra meta. Nuestra vida es un estar-en-camino, Gabriel Marcel nos consideró un homo viator ${ }^{32}$. Dice Ortega: "La auténtica plenitud vital no consiste en la satisfacción, en el logro, en la arribada. Ya decía Cervantes que "el camino es siempre mejor que la posada" ${ }^{33}$. Y en otro lugar añade alguna variación: «Lo importante en la vida es tener quehacer, una misión, una empresa, una tarea. Como Cervantes sugiere, es más sabroso el camino que la posada ${ }^{34}$. El adjetivo empleado por Ortega - sabroso- nos permite recordar que sabio y saber derivan de sapor y sapere $^{35}$. Es decir, el sabio es capaz de gustar y apreciar los distintos sabores de la vida. Por tanto, aspiramos a una condición sapiencial para discernir y vivir la verdad. Esto implica saberse un peregrino del ser o un sustancial emigrante; siempre estamos in via, la vida no es un factum sustantivo sino un faciendum. Vivir es una obra ejecutiva y gerundia, mucho más heraclitiano que parmenidio ${ }^{36}$. Somos un ser que tiene que hacerse a sí mismo, nuestra vida es un proceso in fieri que sólo concluye con la muerte. En cada momento tendremos que dilucidar quién queremos ser o el que queremos seguir siendo ${ }^{37}$. Por esta razón, desoír la

de fuerza —vis, impetus, conatio. La realidad no es otra cosa sino afán. Y del seno de Kant, como el fruto revelador de la simiente, va a emerger frenético Fichte sustentando paladinamente que la filosofía no es contemplación, sino aventura, hazaña, empresa-Tathandlung».

30 Ortega y Gasset, J., Meditación de Europa, O.C. IX, p. 278

31 Ortega y Gasset, J., En torno a Galileo, O.C. V, p. 141: "Como he dicho, el hombre es siempre un venir de algo y un ir a otro algo».

32 Como cantó Antonio Machado: «caminante no hay camino, se hace camino al andar». Recordemos que el poema CXL de Campos de Castilla va precedido de las siguientes palabras: «Al joven meditador José Ortega y Gasset». Por su parte, el filósofo le dedicará un artículo al poeta titulado: Los versos de Antonio Machado. O.C. I, p. 570.

33 Ortega y Gasset, J., La rebelión de las masas, O.C. IV, p. 159. Ortega y Gasset, J., La nación frente al Estado, O.C. X, p. 278: «Una vida noble no es una vida con buen éxito, sino una vida poblada de honrados intentos. Cervantes, nuestro divino y dolorido Cervantes, nos lo dice como un supremo consejo: "Vale más el camino que la posada"».

34 Ortega y Gasset, J., Imperativo de la intelectualidad, O.C. XI, p. 12.

35 Ortega y Gasset, J., Para los niños españoles, O.C. IX, p. 437: "La palabra "sabio" significó en un principio el que distingue de sabores».

36 Ortega y Gasset, J., Meditación de Europa, O.C. IX p. 255: «Pero no es permanencia, sino moverse la sustancia del hombre. Pertenecemos a la simiente de Heráclito, el más genial de los pensadores, pero que siempre ha sido relegado extramuros de la ciudad filosófica, como un malhechor».

37 Ortega y Gasset, J., Vives-Goethe, O.C. IX, p. 558: «el auténtico ser de cada hombre no es una realidad que desde luego le constituye, sino una especie de figura imaginaria, de proyecto irreal, de inexistente aspiración que se ve comprometido a realizar — por tanto, que cada uno de nosotros es propiamente algo que aún no es, que se halla siempre en un futuro problemático: no es un factum, sino un faciendum; no es una cosa, sino una empresa». 
reclamación de nuestro yo equivaldrá a estrangular nuestra vida, ir dimitiendo de nuestras obligaciones más íntimas. Es decir, haber aniquilado nuestro yo y anulado nuestro ser. En suma, haber fracasado como individuos y des-hacernos en la inautenticidad: «Toda vida es, más o menos, una ruina entre cuyos escombros tenemos que descubrir lo que la persona tenía que haber sido» ${ }^{38}$.

Dicho de otra manera, entre todos los proyectos que el hombre elabora y crea libremente, sólo habrá uno mediante el cual cumplirá su auténtico ser. Este es el proyecto vital que estamos llamados a ser (vocación); la fidelidad a este proyecto nos conducirá a la vida auténtica. Somos una vida que debe madurar conforme a nuestro destino. Las personas inauténticas son infieles a su destino. En palabras de Ortega: «Nuestro ser radical, el proyecto de existencia en que consistimos, califica y da uno y otro valor a cuanto nos rodea. De donde resulta que el verdadero Destino es nuestro ser mismo. Lo que fundamentalmente nos pasa es ser el que somos ${ }^{39}$. El destino nos impide vivir a nuestro antojo; es indebido hacer lo que nos venga en gana. El destino nos instiga a ser lo que tenemos que ser. Por consiguiente, no podemos discutirlo o cambiarlo, tan solo podemos aceptarlo o rechazarlo ${ }^{40}$.

La vida auténtica es un proyecto, es decir, comparable a una flecha que se eleva muy por encima del suelo. De este modo podrá llegar muy lejos. Veamos cómo lo expone nuestro filosofo: «Por esta razón nada califica más auténticamente a cada una de las personas que conocemos como la altura de la meta hacia la cual proyecta su vida. La mayor parte rehúye el proyectar, lo cual no es menos proyección. Van a la deriva, sin rumbo propio: han elegido no tener destino aparte y prefieren diluirse en las corrientes colectivas. Otros ponen su vida a metas de escasa altura y no podrá esperarse de ellos sino cosas terre à terre. Pero algunos disparan hacia lo alto su existencia, y esto disciplina automáticamente todos sus actos y ennoblece hasta su régimen cotidiano. El hombre superior no lo es tanto por sus dotes como por sus aspiraciones si por aspiraciones se entiende el efectivo esfuerzo de ascensión y no el creer que se ha llegado» ${ }^{41}$.

Vivir es una empresa transcendental que requiere una gran circunspección. Según la concepción orteguiana, la vida es la realidad primaria y radical, un quehacer que exige todo nuestro compromiso. Vale la pena transcribir un largo pasaje de su obra: «La vida es quehacer; sí, la vida da mucho quehacer, y el mayor de todos es averiguar qué es lo que hay que hacer. Porque en todo instante cada uno de nosotros se encuentra ante muchas cosas que podría hacer, y no tiene más remedio que resolverse por una de ellas. Más, para resolverse por hacer esto

38 Ortega y Gasset, J., Goethe desde dentro, O.C. IV, p. 401.

39 Ortega y Gasset, J., Artículos (1930), O.C. IV, p. 77. Ortega y Gasset, J., La rebelión de las masas, O.C. IV, p. 211: "No es que se deba hacer lo que le dé a uno la gana; es que no se puede hacer sino lo que cada cual tiene que hacer, tiene que ser. Lo único que cabe es negarse a hacer eso que hay que hacer; pero esto no nos deja en franquía para hacer otra cosa que nos dé la gana. En este punto poseemos sólo una libertad negativa de albedrío — la noluntad. Podemos perfectamente desertar de nuestro destino más auténtico; pero es para caer prisioneros en los pisos inferiores de nuestro destino».

40 Ortega y Gasset, J., La rebelión de las masas, O.C. IV, p. 212.

41 Ortega y Gasset, J., Intimidades, O.C. II, p. 644. 
y no aquello tiene, quiera que no, que justificar ante sus propios ojos la elección, es decir, tiene que descubrir cuál de sus acciones posibles en aquel instante da mayor realidad a su vida, la que posee más sentido, la más suya. Si no elige, sabe que se ha engañado a sí mismo, que ha falsificado su propia realidad, que ha aniquilado un instante de su tiempo vital, por cuanto, como dije antes, tiene contados sus instantes. No hay caso de misticismo alguno; es evidente que el hombre no puede dar un solo paso sin justificarlo ante su propio íntimo tribunal» ${ }^{42}$.

En el interior de cada persona encontramos a la vez un reo y un juez. Debemos ratificar nuestra vida ante el veredicto de nuestro fondo insobornable, un incontrovertible tribunal que dictará sentencia. Vivir auténticamente consiste en salvaguardar nuestra existencia, es decir, en dar cumplimiento a las exigencias vitales en forma de proyecto y vocación. Citemos a Sábato: «En la vida existe un valor que permanece muchas veces invisible para los demás, pero que el hombre escucha en el hondo de su alma: es la fidelidad o traición a lo que sentimos como un destino o una vocación que cumplir» ${ }^{43}$. Vivir inauténticamente equivale al descrédito existencial. Acudamos a Laín Entralgo: «el proyecto de vida al cual la vocación misteriosa nos llama es, en parte, "hallado" por nosotros y, en parte, ejecutado por la libre decisión de nuestra voluntad. La "autenticidad" de la existencia depende, en fin de cuentas, de la mayor o menos fidelidad al proyecto que constituye la vocación ${ }^{44}$. Vocación y proyecto van a ser polos indisociables en el seno de la vida, entidades que van a coparticipar en una vida anclada en la autenticidad. Ortega se expresa así: «Vida es anticipación. Cuando de pronto despierto vitalmente y caigo en la cuenta de que vivo me encuentro ya, desde luego, obligado a realizar en el mundo el personaje que soy por anticipado. Y todo lo que hago, es decir, mi presente, lo hago para realizar ese proyecto que soy» ${ }^{45}$.

III

Vivir es proyectarse como un programa vital que tenemos que cristalizar en el mundo. La vida es una operación que se efectúa hacia delante. Nuestra existencia es expectante, la vida de cada persona es profecía permanente y esencial de sí misma. Ortega escribe: «que nuestra vida es, por lo pronto y sobre todo,

42 Ortega y Gasset, J., Lo que más falta hace hoy, O.C. V, 238. Ortega y Gasset, J, Prólogo $a$ "Veinte años de caza mayor»: "Al encontrarse existiendo se encuentra ante un pavoroso vacío. No sabe qué hacer; tiene él mismo que inventarse sus quehaceres y ocupaciones. Si contase con un tiempo infinito ante sí, no importaría mayormente: podría ir haciendo cuanto se le ocurriese, ensayando, una tras otra, todas las ocupaciones imaginables. Pero — ¡ahí está! - la vida es breve y urgente; consiste sobre todo en prisa, y no hay más remedio que escoger un programa de existencia, con exclusión de los restantes; renunciar a ser una cosa para poder ser otra; en suma, preferir unas ocupaciones a las demás».

43 SÁbato, E., La resistencia. Seix Barral. Barcelona. 2000, p. 25

44 Laín Entralgo, P., Obras, Madrid, Plenitud, 1965, p. 72

45 Ortega y Gasset, J., ¿Qué es conocimiento?, p. 133 Larraín, H., La genesis del pensamiento de Ortega, Compañía general fabril editora, Buenos Aires, 1962, p. 140: «El fondo insobornable exhorta imperativamente pero no suprime la libertad. La prueba la tenemos en el hecho de que muchos hombres desoyen esa voz y son infieles a sí mismos». 
proa de sí misma, que anticipa y taja el espumante porvenir, esto es, que lo decide ${ }^{46}$. Existir es anticipar un potencial de actos, proyectarnos en el mundo mediante nuestras acciones. Somos un ser cuya prioridad estriba en ocuparse de su futuro. Toda vida es pre-ocupación: «El porvenir es la inseguridad. Esta inseguridad está administrada, regida por el poder irracional del Azar. Si la vida, dijimos antes, es un sistema de ocupaciones, nuestra primaria ocupación es ocuparnos de nuestro porvenir. Pero el porvenir es lo que aún no es, por tanto, es ocuparnos por anticipado con algo. La ocupación con el porvenir es preocupación. El porvenir nos ocupa porque nos preocupa. Heidegger ha llamado a esto Sorge, pero yo lo llamaba desde muchos años antes "preocupación" »"

Nuestra vida es lo único que tenemos y somos. Vivir implica una doble tarea: inventar la vida (pre-ocupación) y ejecutarla (ocupación) ${ }^{48}$. Existimos originariamente hacia el porvenir, encauzados en su dirección, atraídos por lo que advendrá. El ser más decisivo del hombre radica en ocuparse y pre-ocuparse (tener cuidado) de su futuro. Nos pre-ocupa el porvenir porque no estamos en él y nos resulta desconocido. Continuamente nos proyectamos hacia el porvenir, vigilándolo y preparándonos, esperando lo que pueda acontecer. Primordialmente, somos futurición, un tropel de esperanzas y temores ${ }^{49}$. Avanzamos hacia un futuro que hay que conquistar y afianzar. Vivir es aspiración de ser porque incesantemente sentimos su carácter problemático. Mientras vivimos no podemos tener la seguridad de que dejaremos de hacerlo. Nuestra condición menesterosa e indigente es insoslayable; somos el único ente del universo cuyo ser no consiste en lo que ya es sino en lo que aún no es ${ }^{50}$. En esto consiste la abismática paradoja de nuestra vida. Vivir con autenticidad significa pro-curar que nuestro rumbo existencial sea verdadero. Por tanto, la genuina curiosidad consiste en cuidado y preocupación ${ }^{51}$.

46 Ortega y Gasset, J., Unas lecciones de metafísica, O.C. XII, p. 75.

47 Ortega y Gasset, J., Vives-Goethe, O.C. IX, p. 588. Recordemos que José Gaos traducirá por cura la noción heideggeriana de Sorge. Aranguren, J. L., La ética de Ortega, p. 20: «Es pues evidente que la preocupación orteguiana se distingue claramente de la preocupación o cuidado heideggeriano. La primera es preocupación o invención de la vida. El segundo es, sobre todo, preocupación de la muerte, es angustia».

48 Aranguren, J. L., La ética de Ortega, p. 20.

49 Ortega y Gasset, J., Sobre la razón histórica, O.C. XII, p. 215. En su Antropología metafísica Marías se referirá a la condición futuriza del hombre.

50 Ortega y Gasset, J., Meditación de la técnica, O.C. V, p. 338. Ortega y Gasset, J., Sobre la razón histórica, O.C. XII, pp. 216-217: «Pero, he aquí que el hombre es primariamente "el que no es aún lo que es", sino que tiene que esforzarse en serlo, en luchar para existir, y para existir según su programa y aspiración. El hombre es ahora —en todo ahora-justamente lo que no ha conseguido aún ser. Es, por lo pronto, "lo que le falta". Lejos de ser suficiente, es el ser indigente. [...] El hombre es un haz de privaciones».

51 Ortega y Gasset, J., Unas lecciones de metafísica, O.C. XII, p. 20: «El sentido propio del vocablo "curiosidad" brota de su raíz que da una palabra latina (y sobre la cual nos ha llamado la atención recientemente Heidegger), cura, los cuidados, las cuitas, lo que yo llamo, la preocupación. De cur-a viene cur-iosidad. De aquí que en nuestro lenguaje vulgar un hombre curioso es un hombre cuidadoso, es decir, un hombre que hace con atención y extremo rigor 
Cada uno de nosotros somos primordialmente un ser personalísimo que aspira a convertirse en vida única y particular. Indefectiblemente, tendremos que elegir lo que queremos ser, aspirar a ser elegantes (del latín eligere) ${ }^{52}$. Nuestro filósofo lo expresa así: "¿qué camino, qué vía tomaré para mi vida? Pero la vida no es sino el ser del hombre - por tanto, eso quiere decir lo más extraordinario, extravagante, dramático, paradójico de la condición humana, a saber: que es el hombre la única realidad, la cual no consiste simplemente en ser sino que tiene que elegir su propio ser. Pues si analizásemos ese menudo acontecimiento que va a darse dentro de un rato - el que cada cual tenga que elegir y decidir la dirección de la calle que va a tomar- verían cómo en la elección de una acción en apariencia tan simple interviene íntegra la elección que ya han hecho, que en este momento, sentados, portan secreta en sus penetrales, en su recóndito fondo, de un tipo de humanidad, de un modo de ser hombre que en su vivir procuran realizar» ${ }^{53}$. Son muchos los individuos cuyas vidas no han elegido realmente; que estudian, trabajan o aman sin poder justificar sus actos plenamente, sin preguntarse qué sentido tiene lo que están haciendo. No pueden explicarse cómo han llegado hasta aquí porque no han tomado posesión de su existencia. Nuestros pasos vitales deben conducirse según un plan preconcebido. Las resoluciones puntuales y concretas solo tendrán valor en el contexto holístico del proyecto personal ${ }^{54}$. Nuestro comportamiento no obedece a causas mecánicas y ciegas; actuamos motivados por razones que orientan nuestra vida. Ante las múltiples virtualidades que laten en nuestro ser deberemos responder con firmeza y determinación.

Ese hontanar de actos que es mi vida tiene necesariamente una tendencia y un sentido. Vivir equivale a resolver en hechos nuestra ineludible e inalienable libertad: "Yo tengo que decidir en todo instante lo que voy a hacer en el siguiente y nadie puede tomar esta decisión por mí, sustituirme en ella. [...] En última instancia y verdad, cada cual va llevando a pulso y en vilo su propia existencia» ${ }^{55}$. Yo soy primariamente algo personalísimo que tiene que ser, un proyecto inigualable que calibrará mi autenticidad. Mi vida es el «siendo» de eso que tiene que ser, tal y como ha dicho Sánchez Cámara: «Siendo la vida humana realidad de tal condición, el hombre es el ser que puede vivir bien o mal, mejor o peor, tratando de realizar un proyecto de vida egregio o uno vulgar, auténticamente, realizando su

y pulcritud lo que tiene que hacer, que no se despreocupa de lo que le ocupa, sino, al revés, se preocupa de su ocupación. Todavía en el antiguo español cuidar es preocuparse, curare».

52 Ortega y Gasset, J., Origen y epílogo de la filosofía, O.C. IX. p. 349: «A este acto y hábito del recto elegir llamaban los latinos primero eligentia y luego elegantia. Es, tal vez, de este vocablo del que viene nuestra palabra int-eligencia. De todas suertes, Elegancia debía ser el nombre que diéramos a lo que torpemente llamamos Etica, ya que es esta el arte de elegir la mejor conducta, la ciencia del quehacer. [...] Elegante es el hombre que ni hace ni dice cualquier cosa, sino que hace lo que hay que hacer y dice lo que hay que decir».

53 Ortega y Gasset, J., El hombre y la gente, O.C. VII, p. 103.

54 Ortega y Gasset, J., En torno a Galileo, O.C. V, p. 137: «El vivir, pues, es no poder un paso sin anticipar la dirección o sentido general de cuantos va a dar en su existencia».

55 Ibid., p. 72. 
vocación, o inauténticamente, traicionando su proyecto vital» ${ }^{56}$. Cada persona es primordialmente ese yo que sentimos que debemos y queremos ser.

La vida es una operación que se hace hacia delante, vivir es sentirse disparado hacia el futuro, ya sea cercano o lejano. Por ende, la meta que perseguimos la podemos comparar con aquel objetivo o diana al cual dirigimos esta flecha o proyectil que nosotros somos, en palabras de nuestro filósofo: «No es que en la vida se hagan proyectos, sino que toda vida es en su raíz proyecto, sobre todo si se galvaniza el pleno sentido balístico que reside en la etimología de esta palabra. Nuestra vida es algo que va lanzado por el ámbito de la existencia, es un proyectil, sólo que este proyectil es a la vez quien tiene que elegir su blanco. Nuestra vida va puesta por nosotros a una $u$ otra meta ${ }^{57}$. Podremos hablar de proyecto o como dijera Heidegger, de proyecto-yecto o proyecto arrojado (geworfener Entwurf). La Geworfenheit (estado-de-yecto) es propia de un ser lanzado o arrojado. También se ha traducido como derelicción, en el sentido de abandono. Citemos a Ortega: «Nuestra vida empieza por ser la perpetua sorpresa de existir, sin nuestra anuencia previa, náufragos, en un orbe impremeditado. No nos hemos dado a nosotros la vida, sino que nos la encontramos justamente al encontrarnos con nosotros. (...) Pero la vida en su totalidad y en cada uno de sus instantes tiene algo de pistoletazo que nos es disparado a quemarropa. La vida nos es dada — mejor dicho, nos es arrojada o somos arrojados a ella, pero eso que nos es dado, la vida, es un problema que necesitamos resolver nosotros ${ }^{58}$. Ortega utiliza una de sus metáforas favoritas - el náufrago- para expresar nuestra condición de ser-arrojado. El ser humano vive el punzante sentimiento de haber sido lanzado al mundo sin saber por qué y para qué. Sin previsión, anuncio o preparación previa ingresamos en la existencia, es decir, nos sumergen en una circunstancia. Resulta inevitable remitirnos a Sartre. Este filósofo utiliza - en El existencialismo es un humanismo - el verbo jeter, que podemos traducir por lanzar o arrojar. Existir entraña descubrirse lanzado hacia un porvenir, una existencia consciente de este proyectarse. El hombre será, ante todo, lo que habrá proyectado ser ${ }^{59}$. Recordemos que pro-yecto se forma a partir

56 Sánchez Cámara, I., La teoría de la minoria en Ortega y Gasset, Tecnos, Madrid, 1986, p. 35.

57 Ortega y Gasset, J., El Espectador VII, O.C. II, p. 644.

58 Ortega y Gasset, J., ¿Qué es filosofía?, O.C. VII, p. 417. Ortega y Gasset, J., Unas lecciones de metafísica, O.C. XII, p. 35: "Vivir no es entrar por gusto en un sitio previamente elegido a sabor, como se elige el teatro después de cenar, sino que es encontrarse de pronto y sin saber cómo, caído, sumergido, proyectado en un mundo incanjeable: en éste de ahora». Ibídem, p. 47: «Yo no me he dado la vida, sino, al revés, me encuentro en ella sin quererlo, sin que se me haya consultado previamente ni se me haya pedido la venia».

59 Sartre, J. P., El existencialismo es un humanismo, p. 32. Edhasa. Como escribe este filósofo francés en esta misma obra: «El hombre no es nada más que su proyecto, no existe más que en la medida en que se realiza, no es, por lo tanto, más que el conjunto de sus actos, nada más que su vida». Recordemos a Simone de Beauvoir: «Exister c'est oser se jeter dans le monde» Amorós, C., (Coord.), Feminismo y Filosofía, Madrid, Síntesis, 2000, p. 65: «existencia es sinónimo de proyecto (pro-iaceo) estar lanzado más allá de sí hacia un ámbito de posibilidades abierto del que hay que irse apropiando y hay que ir realizando». 
de pro (hacia delante) y del participio del verbo iacio, que significa lanzar. Por tanto, pro-yectar equivale a lanzar delante de mí. Existir consiste en el despliegue efectivo de lo que sólo existía germinalmente, es decir, pro-yectivamente.

En relación directa con el proyecto que estamos obligados a ser como individuo histórico, hay otro proyecto más profundo y radical, eso que yo en último término soy. Hemos visto cómo mi vida es la realización de un potencial de actos, de un proyecto o programa. Pero no se trata de desempeñar cualquier proyecto, se trata, como nos dijera Píndaro, de llegar a ser el que somos. También en este punto encontraremos concomitancias entre Ortega y Martin Heidegger. Algunos especialistas en Ortega han considerado como decisiva la influencia de Heidegger y su obra magna - El ser y el tiempo- en su concepción en torno a la vida auténtica ${ }^{60}$. Es bien sabido que el filósofo de la Selva Negra tratará esta cuestión; también en su pensamiento el proyecto (Entwurf) ocupará un lugar destacable en tanto que existenciario. Este va a ser uno de los aspectos donde los dos filósofos van a mostrarse próximos. Para Heidegger, el Dasein pro-yecta, es decir, arroja ante sí sus posibilidades como posibilidades, las deja ser en cuanto tales y de este modo se autorrealiza. Citemos al filósofo alemán: «Y sólo porque el ser del Ahí recibe su constitución por medio del comprender y de su carácter proyectivo, y porque él es lo que él llega a ser o no llega a ser, puede decirse a sí mismo, comprendiendo lo que dice: “isé lo que eres!" ${ }^{61}$. A modo de colofón de este apartado, recurramos nuevamente a Ortega: «Somos nuestro destino, somos proyecto irremediable de una cierta existencia. En cada instante de la vida notamos si su realidad coincide o no con nuestro proyecto, y todo lo que hacemos lo hacemos para darle cumplimiento. Porque así como ese proyecto que somos no consiste en un plan libérrimamente dibujado por nuestra fantasía, tampoco se halla ahí, como éste, atenido a nuestro buen deseo de cumplirlo o no. Lejos de esto, es un proyecto que por sí mismo se proyecta sobre nuestra vida, que la oprime rigorosamente porque impone su ejecución. Po eso decía yo antes: el lector es el que tiene que vivir una cierta vida ${ }^{62}$.

60 OsÉs, J. M., La sociología en Ortega y Gasset, Anthropos, Barcelona, 1989, p. 105. Ortega y Gasset, J., Goethe desde dentro, O.C. IV, p. 403: «En el admirable libro de Heidegger titulado Ser y tiempo, y publicado en 1927, se llega a una definición de la vida próxima a ésta. No podría yo decir cuál es la proximidad entre la filosofía de Heidegger y la que ha inspirado siempre mis escritos, entre otras cosas, porque la obra de Heidegger no está aún concluida, ni, por otra parte, mis pensamientos adecuadamente desarrollados en forma impresa; pero necesito declarar que tengo con este autor una deuda muy escasa. Apenas hay uno o dos conceptos importantes de Heidegger que no preexistan, a veces con anterioridad de trece años, en mis libros. Por ejemplo: la idea de la vida como inquietud, preocupación e inseguridad». ORTEga y Gasset, J., Pasado y porvenir para el hombre actual, O.C. IX, p. 631: «Heidegger es siempre profundo, y esto quiere decir que es uno de los más grandes filósofos que haya habido nunca».

${ }_{61}$ Heidegger, M., El Ser y el Tiempo, Fondo de Cultura Económica, México, p. 169. SAFRANSKI, R., p. 186: "A diferencia de los demás entes, el hombre tiene una relación con su propio ser. Heidegger da a esto el nombre de existencia».

62 Ortega y Gasset, J., Artículos (1930), O.C. IV, pp. 77-78. 
3. Reflexiones conclusivas: Proyecto y Realidad Radical ¿Del Sentido al SENTIDO?

\section{I}

La pregunta por el proyecto y su meta final forma parte de la experiencia humana. Sin ella difícilmente podemos hablar con propiedad de vida "humana». Pero aquí aparece rápidamente la pregunta: ¿Qué tipo de respuesta hay que articular? ¿Valen todos sus ensayos? ¿O más bien hay que pasar del sentido particular, de mi vida, al Sentido de la existencia, de la vida, descubriendo lo que tejiendo la trama de la existencia?

Acudiendo a tiempos más recientes, y sin salir de nuestras fronteras, ha sido José Gómez Caffarena (1925-2013) quién ha hecho de la cuestión del sentido la piedra angular de su desarrollo metafísico. En el capítulo VI de su Metafísica Fundamental (1 ${ }^{\mathrm{a}}$ ed, 1969; $2^{\mathrm{a}}$ ed. 1983) aborda la cuestión del sentido, capital para la comprensión de su pensamiento. De hecho, no nos equivocamos al afirmar que toda la obra metafísica de Caffarena es una "metafísica del sentido» ${ }^{3}$ que se desarrolla «desde» $\mathrm{y}$ «para» un mismo elemento, el hombre, y que afronta lo que le importa últimamente: su razón de ser.

La vida humana exige un vector de unidad en su despliegue. Hay una vivencia de proyecto, además de una facticidad, dice Caffarena ${ }^{64}$, ambas reasumidas en las cuestiones del para qué (razón de ser) y del por qué (finalidad). Estas cuestiones existenciales no son, en el fondo, más que preguntas por el sentido, y por eso no pueden ser respondidas desde las ciencias y su metodología ${ }^{65}$. Son preguntas que muchas veces reflejan «momentos» concretos pero que nos implican globalmente, interpelándonos en lo más profundo de nuestra realidad. Son holísticas, afectan al todo, hasta lo no consabido, de nuestras vidas. Se dan por supuestas. Justamente por eso uno no vive su cotidianidad en un continuo escarceo existencial. Solamente se imponen en su fuerza interpelante en situaciones realmente límite (fracaso, culpa, dolor y muerte, como diría Karl Jaspers) que nos empujan a la pregunta por la autenticidad ${ }^{66}$.

Pensemos en el caso de la muerte, que no pocos vinculan con la cuestión del sentido. Gevaert, por ejemplo, apunta que la pregunta por el sentido adquiere

63 Véase Manzana Martínez, J., «Una metafísica del sentido (reflexiones sobre la obra metafísica de José Gómez Caffarena)», en:Pensamiento, vol. 32 (1976), pp. 181-204. En un pasaje afirma: «El "sentido" constituye el centro organizador y sustentador de la reflexión metafísica de Caffarena. La reflexión sólo puede ponerse realmente en camino por un "reconocimiento vital" del sentido de la vida humana. La pregunta por el sentido de la reflexión metafísica conduce, por tanto, en la obra de Caffarena, a una metafísica del sentido. Creemos que Caffarena aceptaría esta "reducción” y no la consideraría como un "empobrecimiento" de la reflexión metafísica, sino como su “esencialización”»(p. 183).

64 Gómez Caffarena, J., Metafísica Fundamental, Cristiandad, Madrid, 1983², p. 148.

65 Gómez Caffarena, J., Metafísica Fundamental, p. 150.

66 Ibid., Metafísica Fundamental, p. 152. 
a través de la muerte una envergadura de «totalidad» ${ }^{67}$. Lo mismo que Von Hildebrand $^{68}$, o el discípulo por antonomasia de Ortega, J. Marías ${ }^{69}$, que subrayan esta íntima vinculación. Si buscamos una expresión más desgarrada de la cuestión, encontramos en la voz de Miguel de Unamuno una canalización harto expresiva: si la muerte es el final, ¿para qué todo? ${ }^{70}$.

La historia del pensamiento es la historia del preguntar humano y en todo cuestionamiento late la pregunta por el sentido. En toda experiencia reaparece la pregunta del por qué $e^{71}$, siempre insistente y tenaz, y a pesar de que la respuesta nunca es clara y distinta, y que además puede ser siempre deconstruída y reducida a asunciones previas y ajenas a la misma cuestión ${ }^{72}$, su ensayo es ineludible. ¿Trágica condición? Quizás, pero no hay otra.

¿Y qué es sentido para Caffarena? Razón de ser, finalidad. Podríamos añadir que entre las acepciones del vocablo «sentido», entra, además de la dirección y la significación, la que tiene que ver con el saepere latino, hecho que nos permite comprenderlo también como la capacidad de saborear la vida ${ }^{73}$. Pero es en todo caso un planteamiento de la totalidad y, por lo tanto, religado a todos los matices que se dan en este despliegue global que llamamos «vida», mi vida. Y puesto que el horizonte definitivo de todo este proyecto es la muerte (M. Heidegger), la radicalidad de su certeza afecta de pleno cualquier juicio sobre un sentido de la "vida»"

Tenemos pues que por un lado el hombre quiere vivir, esto es, plantear un proyecto, una dirección, un sentido a todo su quehacer durante el tiempo que tiene de vida ${ }^{75}$. Y por el otro la muerte, que en tanto que transmisora superlativa de finitud ontológica y amenaza del absurdo representa el fin de la propia realidad radical (término que Caffarena asume como préstamo de Ortega ${ }^{76}$ ), por eso la muerte es la propia perdición. Esta dialéctica, irresoluble, es la que condiciona la experiencia existencial de la vida: aún sabiendo que nuestra vida es una lapso finito, destinada a no ser más ${ }^{77}$, nos anticipamos a dicho fin y nos

67 Gevaert, J., El problema del hombre. Introducción a la antropología filosófica, Ed. Sígueme, Salamanca, 1976, pp. 315-317.

68 Von Hildebrand, D., Sobre la muerte, Encuentro, Madrid, 1983, p. 26.

69 Marías, J., Antropología metafísica, Alianza Editorial, Madrid, 1998, p. 213.

70 Unamuno, M., Del sentimiento trágico de la vida, Ed. Losada, Buenos Aires, 1964, p. 43.

71 Grondin, J., Del sentido de la vida. Un ensayo filosófico, Herder, Barcelona, 2005, p. 15.

72 Ibid., p. 35

73 Ibid., pp. 36-42

74 Así lo afirmaba el jesuita Juan ALFARo (Cf. De la cuestión del hombre a la cuestión de Dios, Ed. Sígueme, Salamanca, 1997, pp. 239-241), maestro y mentor de Caffarena, y director de la investigación doctoral que este realizó sobre Enrique de Gante y que lo condujo a la consecución del título de doctor en filosofía en diciembre de 1956.

75 Alfaro, J., De la cuestión del hombre a la cuestión de Dios, p. 246

76 Cf. EgIDo, J., Fe e Ilustración. El proyecto filosófico de José Gómez Caffarena, UPCO, Madrid, 1999, p. 94.

77 Alfaro, J., De la cuestión del hombre a la cuestión de Dios, p. 245. 
planteamos en nuestra intimidad radical el ser profundo de nuestra existencia y el sentido del proyecto que llevamos a cabo ${ }^{78}$.

Y puede haber más. Es posible que el hombre, como corazón inquietum que es (Agustín de Hipona), no se conforme con respuestas excesivamente formales y marginales a «su» vida, a «su» trabajo a «su» familia. Tarde o temprano la enmienda a la particularidad aparece: no puede sino estar impelido a la cuestión por la totalidad y a la pregunta por la existencia como tal y su gran porqué $^{79}$. Como lo glosa J. Martín Velasco ${ }^{80}$, quien publicó en 1973 un volumen con Caffarena titulado Filosofía de la Religión, el sentido es un plus de ser, un «más» que no se conforma solamente con sobrevivir biofisiológicamente. La pregunta del sentido obliga inapelablemente a dar un salto más allá y a plantearnos, en última instancia, tanto el fundamento último de la vida ${ }^{81}$, como la posibilidad o no de la supervivencia de uno mismo tras la muerte. De esta forma el interrogante del sentido parece llevarnos tarde o temprano a cuestionar la posibilidad de una Trascendencia.

Parece pues que sin Sentido no es posible el sentido. Y sin embargo Viktor Frankl, padre de la logoterapia y cuya experiencia en un campo de exterminio nazi marcó el desarrollo de su vida psicoafectiva, nos propone otra senda: «El sentido de la vida - dice- difiere de un individuo a otro, de un día para otro, de una hora a otra. Así pues, lo que importa no es el sentido de la vida en términos generales, sino el significado concreto de la vida de cada individuo en un momento dado ${ }^{82}$. En consecuencia deberíamos aparcar las grandes preguntas sobre «el» sentido de la vida y pensar concretamente en nuestra particularidad. En el fondo no hay más realidad que la propia, y como todo hombre difiere de su semejante, y por lo tanto el patrón de uno no tiene por qué valer para otro ${ }^{83}$. Cada cual debe construir su propio trayecto vital y la cosmovisión inherente al mismo, y buscar la gran respuesta puede ser, paradójicamente, una irresponsable salida a la irrestricta vocación personal.

Entre una y otra opción, empero, está el justo medio. Como asume Caffarena, la convicción, por muy personal que sea, tiende de algún modo a la universalidad $^{84}$, por lo que topa con cuestiones que nos afectan a todos por igual que van más allá de lo subjetivo. Ciertamente no es lo mismo vivir personalmente la pregunta por el sentido con la esperanza de una vida más allá de la muerte o de un Ser trascendente que funda la esperanza global de bondad, que afirmar la vida como un hecho accidental y sin "propósito» meta-físico. Pero sería

78 Alfaro, J., De la cuestión del hombre a la cuestión de Dios, p. 247.

79 Grondin, J., Del sentido de la vida. Un ensayo filosófico, p. 24. También en Torralba, F. Geografia de l'absurd, Pagès Editors, Lleida, 1993, p. 117.

80 Cf. Martín Velasco, J., Mística i Humanisme, Ed. Cruïlla / Fund. Joan Maragall, Barcelona, 2006, p. 223.

81 Martín Velasco, J., Mística i Humanisme, pp. 19-24.

82 Frankl, V., El hombre en busca de sentido, Ed. Herder, Barcelona, 2001, p. 152.

83 Ibid., pp. 113-114.

84 Gómez Caffarena, J., Metafísica Fundamental, p. 485. 
temerario sostener que quien no asume la efectiva realidad de un Absoluto al modo de un teísta cae irremediablemente en el absurdo. El ejemplo de Ortega es en este punto un claro: es posible asumir la reflexión por la propia vida sin la inflexión de un sentido que refiere a algo transcendente ${ }^{85}$.

Si por sentido hay que entender con Caffarena una opción y un paso adelante, entonces cabe ante la vida una posición optimista. Es la consecuencia directa de su sui generis racional-vitalismo ${ }^{86}$, ya que en el fondo vivir es proclamar «sentido». Pero acabamos de decir que su reverso es el absurdo, una dislocación existencial que viene a nuestra conciencia como vivencia fundamental del mal. No es cuestión aquí de desarrollar el tema en su larga y profusa implicación existencial, sin duda aporéticas para toda afirmación positiva de la existencia como tal. Es suficiente con asumir que «el mal es frustración de un deseo y una necesidad humana. Arguye un desorden». Pero la postura de Caffarena no ceja de recordar asimismo "que el mal que conocemos es un mal parcial que supone necesariamente un bien ${ }^{87}$. Es el clásico malum est privatio boni. $\mathrm{Al}$ ponerse en cuestión el propio valor de ese bien, podemos luchar o resignarnos. Pero eso no implica forzosamente asumir el Bien, en Absoluto. Así da ejemplo la actitud de un Albert Camus, icono de ese hombre que vive la enfermedad y la muerte como privación de vida y que ante ello se «rebela» y se solidariza con los otros hombres en lucha contra ese absurdo que acecha.

No se puede, empero, demostrar nada. Caffarena es muy kantiano también en esto. Pero sí subraya un dato incoado: la propia demostración de algo presupone la posibilidad positiva de mostrar algo, una confianza previa de no absurdidad $^{88}$. Es decir, que es posible acertar, que es posible descubrir que la vida tiene una estructura reconocible y eso, apunta, justamente, al sentido, a que las cosas tienen un sensus, quizás relativo, perfectible, decepcionante, pero en todo caso reconocible. Sin sentido no se podría haber hecho filosofía ${ }^{89}$. Además, el que tiene por absurda la vida es porque espera algo más de ella, y en el fondo la afirma en su valor por encima de lo dado. Si la vida es lo que tenemos, con toda esta contradicción y todo este mal, puede que no tenga mucho sentido, lo que presupone que la vida, como tal, debe ser algo mejor que todo este $\operatorname{caos}^{90}$.

Alguien nos podría alentar a buscar otra vez el justo medio y conceder una tercera opción, intermedia entre el sentido y el absurdo, que permita

85 Una síntesis de la relación de Ortega con el problema de Dios se puede encontrar en Cabria, J. L.; Sánchez-Gey (eds.), J., Dios en el pensamiento hispano del siglo XX, Ediciones Sígueme, Salamanca, 2002.

86 Egido, E., Fe e Ilustración. El proyecto filosófico de José Gómez Caffarena, pp. 122-123.

87 Gómez Caffarena, J., Metafísica Fundamental, p. 154.

$88 \quad$ Ibid., Metafísica Fundamental, p. 157.

89 Ibid., Metafísica Fundamental, p. 153.

90 Grondin, J., Del sentido de la vida. Un ensayo filosófico, p. 26. 
una supresión del juicio y una asunción más o menos tranquila de la cuestión ${ }^{91}$. Pero creemos que en este caso la prudencia es inviable, pues siempre tenemos una opinión última de las cosas, aunque sea la suspensión del juicio. El agnosticismo es, en sí, un posicionamiento metafísico. Seguramente este, como el tesísta, el ateo, o cualquiere que fuere, no se base en juicio o raciocinio puro alguno (como de hecho sostiene la misma perspectiva agnóstica, pues la razón es incapaz en esta materia), sino más bien en las vivencias y en los deseos más o menos conseguidos y fructificados. Por eso dicha opinión se tiene por "opción», asume Caffarena. Así, toda opinión al respecto es también una opción al respecto, y ¿quién podría sostener con sentido que el hecho de no opinar sobre algo no implica ejercer ya una opción respecto a ese algo?

Termina Caffarena la segunda parte de su Metafísica Fundamental, segunda parte de su trilogía metafísica, con una defensa del reconocimiento vital del sentido. Si vivir es ya proclamar sentido, cualquier fe en que la vida tiene sentido (por ejemplo, fe en Dios) se afinca necesariamente en una consideración positiva del hecho de ser hombre y su actuar ${ }^{92}$. No hay refutación del sinsentido, cierto, pero tampoco la hay de la opción de sentido. Lo único cierto es que el hombre está lanzado a la cuestión misma y eso presupone una posible positividad a la pregunta. Es su condición trascendental. El sentido pueda quedar frustrado por los datos vitales experimentados u obtenidos, pero la posibilidad misma de un resultado presupone una posibilidad real, una pre-opción anterior, una abogacía apodíctica por el sentido como ta ${ }^{93}$.

Y en esto sí que seguramente no le falta razón a Caffarena. Dejando de lado eso de que todo sentido particular es dar con el Sentido en mayúscula, es decir, con el entramado último de la existencia ${ }^{94}$, lo cierto es que asumir la opción vital por el sentido es optar y abogar por la posibilidad de una realización suficiente e integral de las posibilidades del hombre. Es haber acertado en la decisión y haber dado con una correcta solución que remite a una verdad: el hombre se lleva a cabo en sus posibilidades totales. Si como dice Ortega estamos radicalmente desorientados ${ }^{95}$, por lo que estar ocupados en nuestra tarea existencial y destino, entonces vivir es decidir, esto es, «hacerse» y proyectar$\mathrm{se}^{96}$, lo que presupone la posibilidad de poder tener éxito en la empresa.

Si el acometido fundamental del hombre es estar ocupado a través del «sentido» consigo mismo, tendrá la necesidad de dar una respuesta al porqué de su opción. Sin sentido no podemos vivir; pero no vale cualquiera, so pena de caer

91 Torralba, F. Geografia de l'absurd, pp. 26-41, plantea esta tercera opción, de la que se distancia.

92 Gómez Caffarena, J. Metafísica Fundamental, p. 159.

93 Ibid., pp. 160-162.

94 Idem.

95 De ahí que la metafísica pueda jugar el rol de ser una reflexión al servicio de la orientación existencial. Cf. ORtega y Gasset, J. Unas lecciones de metafísica, en O.C. XII, p. 44.

96 Ortega y gasset, J. Unas lecciones de metafísica, en O.C. XII, p. 38. 
en arbitrariedades e irracionalismos fundamentalistas poco halagadores. Esa es la esencia de la reflexión filosófica en su máxima expresión.

Universitat Ramon Llul

Guillem Turró Ortega

guillemto@blanquerna.url.edu

Universitat Oberta de Catalunya

Universitat Ramon Llull

Miquel Seguró Mendlewicz

mseguro@rectorat.url.edu

[Artículo aprobado para publicación en enero de 2018] 